\title{
PATTERN OF MAXILLOFACIAL INJURIES DURING COVID-19 PANDEMIC AT BIRAT MEDICAL COLLEGE TEACHING HOSPITAL OF EASTERN NEPAL
}

\author{
Gurung $G^{1 *}$, Chapagain $L P^{1}$, Pokharel $M^{1}$, Thapa $S^{2}$, Parajuli $S B^{3}$
}

\begin{abstract}
Affiliation
1. Lecturer, Department of Dental Surgery; Birat Medical College and Teaching Hospital, Tankisinuwari, Morang, Nepal

2. Dental Surgeon, Department of Dental Surgery; Birat Medical College and Teaching Hospital, Tankisinuwari, Morang, Nepal

3. Assistant Professor, Department of Community Medicine, Birat Medical College and Teaching Hospital, Tankisinuwari, Morang, Nepal
\end{abstract}

\section{ARTICLE INFO}

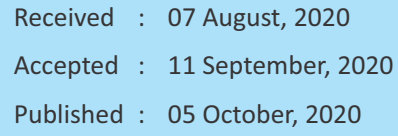

(C) Authors retain copyright and grant the journal right of first publication with the work simultaneously licensed under Creative Commons Attribution License CC - BY 4.0 that allows others to share the work with an acknowledgment of the work's authorship and initial publication in this journal.

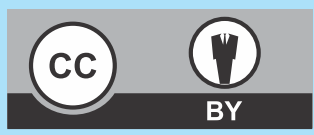

\section{ORA 190}

DOI: https://doi.org/10.3126/bjhs.v5i2.31413

\author{
* Corresponding Author \\ Dr. Gopal Gurung \\ Lecturer \\ Department of Dental Surgery \\ Birat Medical College and Teaching Hospital, \\ Email ID:drgopalomfs@gmail.com \\ ORCID ID: https://orcid.org/0000-0002-7884-7899
}

\section{Citation}

Gurung G, Chapagain LP, Pokharel M, Thapa S, Parajuli SB. Pattern of Maxillofacial Injuries during COVID-19 Pandemic at Birat Medical College Teaching Hospital of Eastern Nepal. BJHS 2020; 5(2)12:1099-1103.

\section{ABSTRACT}

\section{Introduction}

Maxillofacial injuries are one of the most common injuries seen in trauma patients. Road traffic accidents (RTA) are the most common cause of maxillofacial injuries all over the world. RTA are supposed to decrease due to lockdown which has become a usual phenomenon during the COVID19 pandemic. Changes in the etiology of maxillofacial injuries are supposed to dictate their pattern as well.

\section{Objectives}

The objective of this study was to assess the pattern of maxillofacial injuries during the COVID-19 Pandemic at Birat Medical College and Teaching Hospital.

\section{Methodology}

A cross-sectional study was conducted among the patients attending Birat Medical College and Teaching Hospital for the treatment of maxillofacial injuries from 1 May to 31 July 2020. Consecutive sampling was used to collect data from 52 study participants.

\section{Results}

A total of 52 patients with maxillofacial injuries were studied. The age of patients ranged from 1 year to 73 years with a median age of 26 years. There were $69.2 \%(n=36)$ males with a male to female ratio of 2.25:1. The most common etiology was Road Traffic Accidents $(50 \%, n=26)$. Laceration $(70.7 \%, \mathrm{n}=29)$ was the most common soft tissue injury. Parasymphysisfracture $(23.8 \%, n=5)$ was the most common site of mandible fracture. The most common midface fracture was the zygomaticomaxillary complex (ZMC) fracture $(40.9 \%, n=9)$.

\section{Conclusion}

RTA still remains the most common etiology of maxillofacial injuries in spite of COVID-19 and the pattern of maxillofacial injuries has not changed much either.

\section{KEYWORDS}

COVID-19, fracture, mandible, maxillofacial injuries 


\section{INTRODUCTION}

Maxillofacial injuries are one of the most common injuries seen in trauma patients. Maxillofacial injuries may present as soft tissue injuries such as abrasion, contusion, laceration, and avulsion. It may also present as fractures of facial bones in the form of Lefort I, Lefort II, Lefort III fractures, zygomaticomaxillary complex fracture (ZMC), zygomatic arch fracture, blow out fracture of orbit, naso-orbitoethmoidal (NOE) complex fracture, fracture of the mandible, etc. Maxillofacial injuries may present solely or maybe in combination with injuries to other parts of the body as well. Maxillofacial injuries alone are rarely fatal however if they have a serious impact on the airway, breathing and circulation may lead to death as well. Maxillofacial injuries are emergencies that require extensive management based on their presentation. Maxillofacial injuries are associated with several anatomic structures such as the eye, ear, nose, oral cavity. So injuries to the maxillofacial area have a serious effect on the quality of life. ${ }^{1}$ Maxillofacial injuries are often associated with severe morbidity, loss of function, substantial financial cost and disfigurement. ${ }^{2}$

There are various etiologies of maxillofacial injuries such as Road Traffic Accidents (RTA), fall, assault, sports-related injuries, war, industrial accidents, animal attacks, etc. RTA remains the most common cause of maxillofacial injuries all over the world, although there is a decreasing trend, particularly in North America and Brazil, and Europe. In these continents, assaults and falls have become more important. In Asia and Africa RTA remains the most common etiology. ${ }^{3}$

The World Health Organization (WHO) declared COVID-19 as a pandemic on 11 March 2020 as it started to spread around the world. The world has responded to the COVID-19 pandemic by lockdown and behavior modifications like washing hands with soaps, using sanitizers, wearing masks, measuring temperatures at entry points, and maintaining social distance. It seems that preventive measures such as travel restriction, social distancing will remain in place for a long time. Various studies done in Nepal, prior to the COVID19 pandemic have shown RTA to be the main etiology of the maxillofacial injuries. ${ }^{4-9}$ GUO Yu-Xuan et al in their study done during the COVID-19 epidemic showed fall to be the main cause of the facial injury rather than a traffic accident. ${ }^{10}$ There is a gap in the knowledge of the pattern of maxillofacial injuries during the COVID-19 pandemic. Epidemiological assessments of maxillofacial injuries during this COVID-19 pandemic will be crucial to identify patterns of maxillofacial injuries. It will help to initiate preventive measures as per the pattern of maxillofacial injuries.

\section{METHODOLOGY}

We conducted a cross-sectional study among patients attending Birat Medical College and Teaching Hospital for the treatment of maxillofacial injuries from 1 May to 31 July
2020. Consecutive sampling was used to collect data from 52 study participants. Ethical clearance was taken from the Institutional Review Committee of Birat Medical College and Teaching Hospital, prior to the study. Informed consent was taken from study participants and from parents if the age of the participants was less than 18 years. All the patients with maxillofacial injuries who visited the Emergency department and Dental outpatient department for treatment were included in the study. Patients not willing to be enrolled in the study were excluded. Patient demographics, cause of injury, associated injuries to other parts of the body, alcohol consumption, soft tissue injuries, and facial bone fractures, and treatment done were recorded in a preformed Proforma. The etiology of maxillofacial injuries was divided into RTA, fall, physical assault, industrial, and blast. Alcohol consumption by the patient at the time of trauma was also noted. Soft tissue injuries were classified as abrasion, contusion, laceration, and avulsion of the face. Fracture of the midface was divided into Lefort I, Lefort II, Lefort III, NOE, ZMC, infraorbital fracture, and dentoalveolar fracture. Fracture of the mandible was divided into different types based on its anatomical structures such as condyle, coronoid, ramus, angle, body, parasymphysis, symphysis, and dentoalveolar fracture. Associated injuries to other parts of the body were recorded as Head injuries, Orthopedicinjuries, Chest injuries, and Abdomen injuries. Data were entered in Microsoft Excel and analyzed by Statistical Package for Social Sciences (SPSS) version 23

\section{RESULTS}

A total of 52 patients with maxillofacial injuries were studied. The age of patients ranged from 1 year to 73 years with a median age of 26 years. The majority of cases were in the third decade of life $(38.4 \%, n=20)$ followed by the second decade of life $(19.2 \%, n=10)$ and least in the age group above the sixth decade of life $(3.9 \%, n=2)$ (Table 1$)$. There were $69.2 \%(n=36)$ males and females $30.8 \%(n=16)$ with a male to female ratio of 2.25:1.

Table 1: Age wise distribution of patients $(n=52)$

Age (years)

Numbers (\%)

Below 10

$5(9.7)$

$11-20$

10(19.2)

$21-30$

20(38.4)

$31-40$

6(11.5)

41-50

$4(7.6)$

50-60

$5(9.7)$

Above 60

2(3.9) 
The most common etiology was RTA $(50 \%, n=26)$ followed by fall $(34.7 \%, n=18)$ (Table 2). There were six (11.5\%) patients that reported with physical assault and one (1.9\%) reported with an industrial accident with a crusher. one (1.9\%) reported with blast injuries due to the explosion of a liquefied petroleum gas cylinder. Alcohol consumption was associated with $23 \%(n=12)$ of maxillofacial injuries.

Table 2: Etiology of maxillofacial injuries $(\mathrm{n}=52)$
\begin{tabular}{|l|c|}
\hline Etiology & Numbers (\%) \\
\hline RTA & $26(50)$ \\
\hline Fall & $18(34.7)$ \\
\hline Physical assault & $6(11.5)$ \\
\hline Industrial & $1(1.9)$ \\
\hline Blast & $1(1.9)$ \\
\hline
\end{tabular}

There were 41 soft tissue injuries among 36 patients. Isolated soft tissue injuries were seen in 24 patients. The most common soft tissue injury was laceration $(70.7 \%$, $\mathrm{n}=29$ ) followed by abrasion $(14.6 \%, \mathrm{n}=6)$ (Figure 1 ). Contusion was seen in $9.8 \%(n=4)$ and avulsion of face in $4.9 \%(n=2)$.

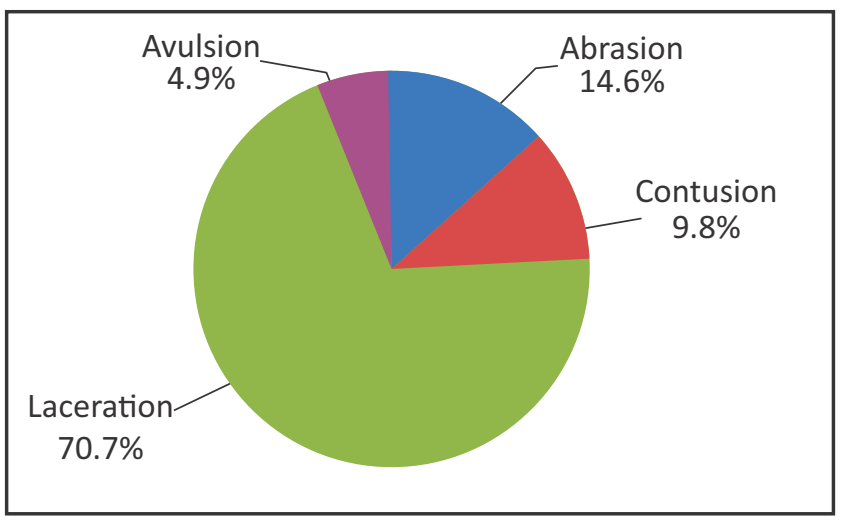

Figure 1: Pattern of soft tissue injuries

There were 28 patients with 43 facial bone fractures. The isolated bone fracture was seen in 15 patients. The most common fracture of the mandible was parasymphysis $(23.8 \%, n=5)$ followed by symphysis $(19 \%, n=4)$ (Table 3$)$. Condylar fracture, body fracture, and mandibular dentolaveolar fracture were in equal percentage (14.3\%, $n=3)$. There was coronoid fracture in $9.5 \%(n=2)$ and ramus fracture in one $4.8 \%(n=1)$. Most common midface fracture was zygomaticomaxillary complex (ZMC) fracture $(40.9 \%$, $n=9)$ followed by maxillary dentoalveolar fracture $(27.3 \%$, $n=6)$. Lefort II and III fracture were in equal percentage each $9 \%(n=2)$. There was an equal percentage of Lefort I, NOE, and infraorbital fracture, each $4.6 \%(n=1)$. The maxillary dentoalveolar fracture $(27.3 \%, n=6)$ was more common than mandibular $(14.3 \%, \mathrm{n}=3)$.

Table 3: Pattern of Facial bone Fracture
\begin{tabular}{|l|c|}
\hline Pattern of Mandible fracture & Numbers (\%) \\
\hline Symphysis & $4(19.0)$ \\
\hline Parasymphysis & $5(23.8)$ \\
\hline Body & $3(14.3)$ \\
\hline Ramus & $1(4.8)$ \\
\hline Coronoid & $2(9.5)$ \\
\hline Condyle & $3(14.3)$ \\
\hline Dentoalveolar & $3(14.3)$ \\
\hline Total & $21(100 \%)$ \\
\hline Pattern of Midface fracture & Numbers (\%) \\
\hline Lefort I & $1(4.6)$ \\
\hline Lefort II & $2(9.0)$ \\
\hline Lefort III & $2(9.0)$ \\
\hline NOE & $1(4.6)$ \\
\hline ZMC & $9(40.9)$ \\
\hline Infraorbital & $1(4.6)$ \\
\hline Dentoalveolar & $6(27.3)$ \\
\hline Total & $22(100 \%)$ \\
\hline
\end{tabular}

Out of 34 facial bone fractures excluding dentoalveolar fracture, $15(44.15 \%)$ were managed by open reduction and internal fixation (ORIF), 4 by closed reduction, and 15 conservatively. Dentoalveolar injuries were managed by splinting. All lacerations $(n=29)$ were sutured under local anesthesia and avulsion of face $(n=2)$ were sutured under general anesthesia. There were 12 patients with 16 associated injuries to other parts of the body. The most common associated injury was head injury $(43.7 \%, n=7)$ followed by orthopedic and chest injuries each $25 \%(n=4)$ (Figure 2). Abdomen injuries was seen in one patient (6.3\%) only.
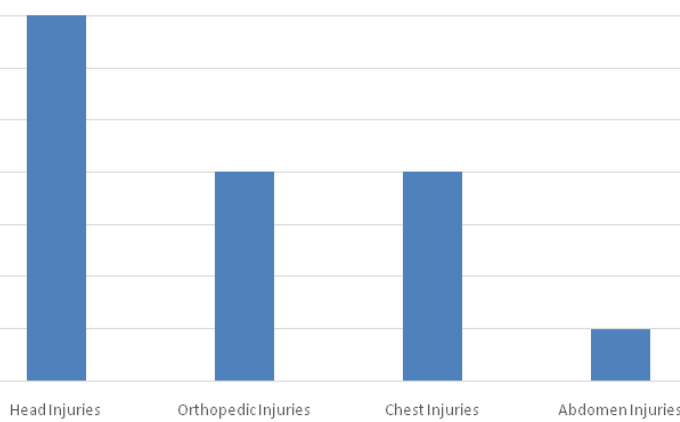

Figure 2: Associated injuries with Maxillofacial Injuries 


\section{DISCUSSION}

COVID-19 has affected each and every field. Oral and maxillofacial surgery specialty have been affected by the COVID-19 pandemic as well. There have been changes in the maxillofacial practices according to various guidelines to combat COVID-19. ${ }^{11,12}$ In our study, the majority of cases were in the third decade of life $(38.4 \%, n=20)$ as found in other studies done in Nepal prior to the COVID-19 pandemic. ${ }^{6,79}$ This age group is active and they have more responsibilities for the livelihood of their families so they have to venture out more compared to other age groups even in this pandemic. This age group has a phase of great personal independence, social excitement, and exposure to violence as well. ${ }^{13,14}$ Findings of male to female ratio of 2.25:1 is similar to other studies of Khadka et al and Pradhan et al. This may be due to our society being patriarchal, male have more responsibilities of family and have to go outdoors frequently. Male also have active social life and alcohol consumption habits that expose them to maxillofacial injuries. ${ }^{15}$ In Southeast Asian countries RTA remains the most common etiology of maxillofacial injuries. ${ }^{16,17,18}$ Chemma et al from Pakistan reported RTA (54\%, $n=382$ ), similarly, Weihsin et al from India reported RTA (53\%, n = $2347)$ to be the most common cause of maxillofacial injuries. ${ }^{16,17}$ Another study from Bangladesh by Sultan et al have reported RTA $(54.02 \%, n=235)$ as the most common cause of maxillofacial injuries. ${ }^{18}$ We found RTA $(50 \%, n=26)$ as the most common etiology followed by fall $(34.7 \%, n=18)$ even in time of pandemic of COVID-19 which is in contrast to the study from china by GUO Yu-xuan et al. They had reported fall as the main etiology of maxillofacial injuries during the COVID-19 pandemic. ${ }^{10}$ This may be due to their study duration of being less than one month and was carried out from 23 January to 20 February 2020 at the peak of the lockdown period. Another explanation could be due to lockdown not being properly followed in the initial phase and being partially removed after one and half months in Nepal. However the proportion of RTA have reduced and fall have increased compared to studies done in Nepal prior to the pandemic of COVID-19 as reported by Subedi et al (RTA $88 \%$, fall $4.2 \%$ )and Biswari et al (RTA $64 \%$, fall $16 \%$ ),

Alcohol consumption was associated with $23 \%(n=12)$ of maxillofacial injuries in our study. Alcohol consumption is known to increase crash likelihood due to reflex reduction, the abuse of velocity, and neglect of safety measures, and an increase in violent behavior. ${ }^{19}$ The most common soft tissue injury was laceration $(70.8 \%, n=29)$ similar to other studies. $^{7,20}$ In a similar study by Pradhan et al, 229 patients had various form of soft tissue injuries and lacerations (59.8\%, n=137) was the most common soft tissue injuries. ${ }^{7}$ Another study from Malaysia by Hussaini et al also reported laceration as the most common soft tissue injuries (69\%, $\mathrm{n}=203) .{ }^{20}$ Mandible $(48.8 \%, \mathrm{n}=21)$ is the most common site of facial bone fracture as in other studies..$^{5-7,9,21,22}$ Pandey et al studied a total of 1,108 patients with maxillofacial fractures and reported mandible as the most frequently fractured facial bone $(33.57 \%, n=372) .{ }^{22}$ Mandible is more susceptible to fracture because of its prominence and being the only movable facial bone. The most common fracture of the mandible was parasymphysis $(23.8 \%, n=5)$ similar to other studies. $^{5-7,9,23}$ Adhikari et al reported parasymphysis (35\%, $n=42$ ), as the most common site of mandible fracture. ${ }^{23}$ The most common midface fracture was ZMC fracture $(40.9 \%, n=9)$ in our study which is similar to study done by Subedi et al. ${ }^{6}$ Subedi et al reported ZMC fracture in 67 (42\%) patients. The prominent convex shape of zygoma makes it vulnerable to fracture. ${ }^{24}$ The most common associated injury was head injury $(43.7 \%, n=7)$ as seen in other studies. ${ }^{7,9}$ Study done by Pradhan et al in Nepal have reported head injury in $58.7 \%(n=37)$ patients.

Out of 34 facial bone fractures excluding dentoalveolar fracture, 19 (54.2\%) were managed by closed reduction and conservative management. Maxillofacial fracture management by open reduction and internal fixation is an aerosol generating procedure that is associated with an increased risk of transmission of the virus so, closed reduction and conservative management were preferred. Guidelines given by Arbeitsgemeinschaft für Osteosynthesefragen craniomaxillofacial (AO CMF) for COVID-19 Pandemic advocates closed treatment for maxillofacial fractures to reduce risk of COVID-19. ${ }^{12}$

\section{CONCLUSION}

The proportion of RTA to other etiologies of maxillofacial injuries has decreased. However, RTA still remains the most common etiology of maxillofacial injuries during this COVID19 pandemic. The pattern of maxillofacial injuries has not changed much either in this COVID-19 pandemic.

\section{RECOMMENDATIONS}

Further multicenter studies with more sample size and duration are required to evaluate the accurate pattern of maxillofacial injuries during the COVID-19 pandemic.

\section{LIMITATIONS OF THE STUDY}

This study was done at a single center.

\section{ACKNOWLEDGEMENTS}

We would like to acknowledge the study participants, Department of Dental surgery and Emergency Department of Birat Medical College and Teaching Hospital.

\section{CONFLICT OF INTERESTS}

The authors declare no conflict of interest

\section{FINANCIAL DISCLOSURE}

None 


\section{REFERENCES}

1. Peter WB. Maxillofacial trauma and esthetic facial reconstruction. 2nded.St.Louis:Saunders; $2012.3 p$.

2. Kieser J, Stephenson S, Liston PN, Tong DC, Langley JD. Serious facial fractures in New Zealand from 1979 to 1998. Int J Oral Maxillofac Surg. 2002;31(2):206-209. doi:10.1054/ijom.2002.0208

3. Boffano P, Kommers SC, Karagozoglu KH, Forouzanfar T. Aetiology of maxillofacial fractures: A review of published studies during the last 30 years. Br J OralMaxillofac Surg.2014;52(10):901-906. doi:10.1016/j.bjoms.2014.08.007

4. Biswari G, Khanal A, Gupta P, Bansal P. Evaluation of maxillofacial injury in the central part of Nepal. J Coll Med Sci. 2012;7(3):11-16. doi:10.3126/jcmsn.v7i3.6702

5. KhadkaR,Chaurasia N. Four years prospective study of the maxillofacial trauma at a tertiary center in Western Nepal. J Orofac Sci. 2014;6(2):78. doi:10.4103/0975-8844.143044

6. Subedi S, Shrestha B, Adhikari R. Pattern of Maxillofacial fracture in Western and Central Nepal: An experience in 3 tertiary level health institutions.JColl Med Sci. 2015;10(3):8-13. doi:10.3126/jcmsn. v10i3.12771

7. Pradhan L, Jaisani MR, Dulal S, Dongol A, Sagtani A. A study on the pattern of maxillofacial injury in patients reporting to a tertiary care hospital in eastern Nepal. J Oral Maxillofac Surgery, Med Pathol. 2015;27(5):656-661. doi:10.1016/j.ajoms.2015.01.012

8. K.C. K, Shrestha JM. Maxillofacial injuries managed at Tribhuvan University Teaching Hospital, Kathmandu, Nepal: a 7 year retrospective study. J SocSurg Nepal. 2016;19(1):4-8. doi:10.3126/ jssn.v19i1.24548

9. Mahat AK, Gurung G, Shrestha M, Chaudhary B. Epidemiology of Maxillofacial Fracture - A Hospital Based Study. J Nepalgunj Med Coll. 2020;17(2):23-27. doi:10.3126/jngmc.v17i2.28756

10. GUO Yu-xuan,CONG Bing-feng,LUJin-biao, Yang Yong,LIU Yi-wen, DING Ming-chao et al. Clinical analysis of 25 oral and maxillofacial emergency patients during the period of COVID-19 epidemic[J]. China Journal of Oral and Maxillofacial Surgery, 2020, 18(2): 105110.doi: $10.19438 /$ j.cjoms.2020.02.003

11. French Society of Stomatology, Maxillo-Facial Surgery, Oral Surgery (SFSCMFCO).Practitioners specialized in oral health and coronavirus disease 2019: Professional guidelines from the French society of stomatology, maxillofacial surgery and oral surgery, to form a common front against the infectious risk. J Stomatol Oral Maxillofac Surg. 2020;121(2):155-158. doi:10.1016/j.jormas.2020.03.011

12. $\mathrm{AO} C \mathrm{CMF}$ International Task Force. $\mathrm{AO} C \mathrm{CMF}$ International Task Force Recommendations on Best Practices for Maxillofacial Procedures during COVID-19 Pandemic.https://aocmf3.aofoundation.org//media/project/aocmf/aocmf/files/covid-19/ao_cmf_covid19_task_force_guidelines_v1-6.pdf
13. Lee KH, Snape L, Steenberg LJ, Worthington J. Comparison between interpersonal violence and motor vehicle accidents in the aetiology of maxillofacial fractures. ANZ J Surg. 2007;77:695-8.doi: 10.1111/j. 1445-2197.2007.04189.x

14. Motamedi MH. An assessment of maxillofacial fractures: a 5-year study of 237 patients. J Oral Maxillofac Surg. 2003;61:614.doi:10.1053/joms.2003.50049

15. Gomes PP, Passeri LA, Barbosa JR. A 5-year retrospective study of zygomatico-orbital complex and zygomatic arch fractures in Sao Paulo State, Brazil. J Oral Maxillofac Surg. 2006;64(1):63-7.doi: 10.1016/j.joms.2005.09.012.

16. Cheema SA, Amin F. Incidence and causes of maxillofacial skeletal injuries at the Mayo Hospital in Lahore, Pakistan. Br J Oral MaxillofacSurg 2006;44:232-4.doi:10.1016/j.bjoms.2005.05.017

17. Weihsin H, Thadani S, Agrawal M, Tailor S, Sood,RLangalia A et al.Causes and incidence of maxillofacial injuries in India: 12-year retrospective study of 4437 patients in a tertiary hospital in Gujarat Br J Oral MaxillofacSurg, 52 (2014):693-696. doi:10.1016/ j.bjoms.2014.07.003

18. Sultana F, Karim MR, Haider IA. Epidemiological \& Clinical Profile of Patients Presented with Mandible Fracture in a Tertiary Care Hospital. J Bangladesh Coll Physicians Surg. 2018;36(3):107-111. doi:10.3329/jbcps.v36i3.37034

19. Leles JLR, dos Santos ÊJ, Jorge FD, da Silva ET, Leles CR. Risk factors for maxillofacial injuries in a Brazilian emergency hospital sample. J Appl Oral Sci. 2010;18(1):23-29. doi:10.1590/S1678-77572010000100006

20. Hussaini HM, Rahman NA, Rahman RA, Nor GM, Al Idrus SM, Ramli R. Maxillofacial trauma with emphasis on soft-tissue injuries in Malaysia. Int J Oral Maxillofac Surg. 2007;36(9):797-801. doi: 10.1016/j.ijom.2007.04.004

21. Kapoor P, Kalra N. A retrospective analysis of maxillofacial injuries in patients reporting to a tertiary care hospital in East Delhi. Int J CritlllnInj Sci. 2012;2(1):6. doi:10.4103/2229-5151.94872

22. Pandey S, Roychoudhury A, Bhutia O, Singhal M, Sagar S, Pandey RM. Study of the Pattern of Maxillofacial Fractures Seen at a Tertiary Care Hospital in North India. J Maxillofac Oral Surg. 2015;14(1):32-39. doi:10.1007/s12663-013-0578-4

23. AdhikariRB ,Karmacharya A MN. Pattern of mandibular fractures in western region of Nepal. Nepal J Med Sci. 2012;1(1):45-8.

24. Covington DS, Wainwright DJ, Teichgraeber JF, Parks DH. Changing patterns in the epidemiology and treatment of zygoma fractures: $10-$ year review. J Trauma 1994;37:243-8.doi: 10.1097/00005373199408000-00016 